www.volsu.ru

DOI: https://doi.org/10.15688/jvolsu3.2017.2.12

UDC 336.051

LBC 65.291.2

\title{
WAYS OF IMPROVING THE ACCURACY OF THE COMPANIES' VALUATION IN THE CONDITIONS OF FINANCIAL CRISIS
}

\author{
Yuliya A. Kaftulina \\ Penza State University, Penza, Russian Federation \\ Vera N. Batova \\ Penza State University, Penza, Russian Federation
}

Inna A. Mitrofanova

Volgograd State Technical University, Volgograd, Russian Federation

Yuliya I. Rusakova

Penza State University, Penza, Russian Federation

\begin{abstract}
Today Russia's economy is going through just another financial crisis, which was triggered by the imposition of sanctions. The sanctions were imposed against Russia because of its position on the "Ukrainian issue". Economic instability has an impact on many areas of activity, including the valuation one. As a rule, during the crisis, the accuracy of estimation reports is greatly reduced. In this regard, the study of possible ways of improving the accuracy of business valuation is relevant.

The main purpose of the article is to identify the possible ways of improving the accuracy of companies' valuation in the conditions of economic instability.

Results. The authors identify and describe the practical methods for determining the amendments for discount $\underset{N}{ }$ factor in the income approach. The expediency of applying each of the three classical approaches during the crisis $\therefore$ is substantiated.

Conclusions. During the period of economic instability it is necessary to improve the classical approaches to business valuation. This can be done through the introduction of various amendments. Obtaining the high-quality initial information by appraisers can contribute to improving the accuracy of valuation reports.

The authors work out a number of recommendations to account for the influence of macroeconomic indicators in the valuation during the crisis by introducing amendments to the coefficient of discounting.

Key words: crisis, sanctions, valuation, valuation methods, financial market, financial crisis, capitalization, discounting coefficient.

УДК 336.051

ББК 65.291 .2

\section{ПУТИ ПОВЫШЕНИЯ ТОЧНОСТИ ОЦЕНКИ СТОИМОСТИ КОМПАНИЙ} В УСЛОВИЯХ ФИНАНСОВОГО КРИЗИСА
\end{abstract}

\author{
Юлия Анатольевна Кафтулина
}

Пензенский государственный университет, г. Пенза, Российская Федерация

Вера Николаевна Батова

Пензенский государственный университет, г. Пенза, Российская Федерация

\section{Инна Алексеевна Митрофанова}

Волгоградский государственный технический университет, г. Волгоград, Российская Федерация 


\section{Юлия Игоревна Русакова}

Пензенский государственный университет, г. Пенза, Российская Федерация

Аннотация. Сегодня экономика России переживает очередной финансовый кризис, который был спровоцирован введением санкций. Санкции были введены против России вследствие ее позиции относительно «украинского вопроса». Экономическая нестабильность оказывает влияние на многие сферы деятельности, в том числе и на оценочную. Как правило, в период кризиса точность отчетов об оценке значительно снижается. В связи с этим исследование возможных путей повышения точности оценки бизнеса является актуальной исследовательской задачей.

Целью работы является выявление возможных способов повышения точности оценки компаний в условиях экономической нестабильности. Авторами выявлены и охарактеризованы практические приемы определения поправки для коэффициента дисконтирования в доходном подходе; обоснована целесообразность применения каждого из трех классических подходов в условиях кризиса.

Обосновано, что в период экономической нестабильности возникает необходимость совершенствования классических подходов к оценке бизнеса. Сделать это возможно с помощью введения различных поправок. Повышению точности отчетов об оценке будет способствовать получение оценщиками более качественной исходной информации.

Авторами разработан ряд рекомендаций для учета влияния макроэкономических показателей при оценке стоимости в условиях кризиса путем введения поправок в коэффициент дисконтирования.

Ключевые слова: кризис, санкции, оценка стоимости, методы оценки стоимости, финансовый рынок, финансовый кризис, капитализация, коэффициент дисконтирования.

В период экономической нестабильности наибольшему воздействию подвергается финансовый сектор [24]. Изменения на финансовых рынках и в экономике в целом отражаются на результатах деятельности компаний, в частности, на их стоимости.

Бизнес - это особая деятельность, сформированная в пределах конкретной структуры, главная цель которой - извлечение максимальной прибыли. Таким образом, капитал компании - это основа, внутреннее содержание каждого процесса создания товара или услуг с целью получения прибыли.

Бизнес (предприятие, компания) - обособленный вид товара. В экономической теории товар имеет, по крайней мере, два свойства: быть пригодным к обмену и обладать способностью удовлетворять какие-либо человеческие потребности. Хозяин организации вправе перепродать ее, заложить, подарить, обменять. Таким образом, организация становится предметом купли-продажи, то есть это объект, имеющий свойства и характеристики товара. Как любой товар, предприятие имеет свойство приносить пользу для покупателя. Он должен быть способным соответствовать потребности извлечения дохода. Также как и у иного другого товара, полезность предприятия осуществляется в пользовании [13].
В современных экономических условиях сделки по купле-продаже, слиянию или дроблению бизнеса стали обычным явлением деловой практики. При этом одним из основных критериев успешного управления бизнесом является непрерывный рост его стоимости, прежде всего определяемый такими внутренними факторами, как инвестиционная, операционная и финансовая деятельность хозяйствующих субъектов. В большинстве случаев как зарубежные, так и отечественные авторы относят инвестиционную деятельность к числу основных факторов, позитивно влияющих на стоимость компаний. Как отмечают В.В. Яновский и С.В. Проскурников, «...данный контекст справедлив лишь в том случае, когда показатели оценки стоимости бизнеса присутствуют в составе критериев эффективности, используемых в процессе экономического обоснования инвестиций» [25].

Действительно, показатель стоимости бизнеса является важным фактором для инвесторов при решении вопроса о вложении средств в конкретную организацию.

Согласно существующей философии, основанной на оценке стоимости бизнеса, данная концепция является основным критерием эффективности менеджмента, что признано в настоящее время большинством зарубежных исследователей и практиков. По оценке многих специалистов, единственной целью деятельности компа- 
нии, позволяющей примирить и согласовать все остальные частные цели функционирования, является рост стоимости компании.

В Российской Федерации по мере становления рыночных условий хозяйствования значительно чаще стали возникать ситуации, когда необходимым элементом становится проведение оценки. Бурный рост рынка недвижимости спровоцировал формирование спроса на оценку ее рыночной стоимости в первую очередь. Впоследствии потребность в достоверной оценке тех или иных объектов собственности было вызвано развитием кредитных, страховых и арендных отношений, отношений, связанных с куплей-продажей промышленной недвижимости и других объектов основных средств, разработкой бизнес-планов инвестиционных проектов, ситуаций, связанных с банкротством, слиянием и разделением хозяйствующих субъектов, проведением аукционов и конкурсов по продаже пакетов акций предприятий и т. д.

В нашей стране до недавнего времени оценка рассматривалась в отрыве от целей и задач стратегического и финансового менеджмента. Как утверждает большинство исследователей, оценка стоимости бизнеса сама по себе не имеет институционального значения. Такое значение оценочная деятельность приобретает только тогда, когда она становится частью работы менеджеров по управлению активами компании. Из этого следует, что любые серьезные управленческие решения должны апробироваться с помощью оценок стоимости бизнеса [19].

Однако в период экономической нестабильности становится трудно учесть все финансовые и нефинансовые риски, в связи с чем показатель стоимости компаний перестает удовлетворять требованиям адекватности.

Управление стоимостью компании (бизнеса) - это целенаправленное воздействие со стороны менеджеров и собственников предприятия на величину его стоимости, осуществляемое с целью максимизации ее величины [1]. Оценка стоимости компании (бизнеса) включает в себя, с одной стороны, отношение к оцениваемому экономическому субъекту со стороны общественно-экономической среды, называемой рынком, а с другой стороны - отношение к тому же предприятию отдельного лица. В последнем случае компания (бизнес) оценивается с субъективных позиций, но в объективных условиях рынка [9].

Действие санкций и антисанкций, волатильность на финансовых и сырьевых рынках, глубокие социальные преобразования, осуществляемые наряду с процессами преодоления экономического кризиса, актуализировали исследования тенденций, сценариев и факторов регионального развития в условиях новых экономико-политических реалий [2].

И поскольку санкции существенно ограничили доступ многих отечественных компаний на международные финансовые рынки, создав тем самым дополнительные трудности при финансировании экономики, вызывает, по меньшей мере, недоумение тот факт, что это ужесточение внешней среды сопровождается не смягчением, а ужесточением внутренних подходов регуляторов. Последние должны были бы, напротив, создать максимально комфортные условия для бизнеса, нейтрализуя тем самым возникшие новые трудности. В целом в сложившихся новых условиях важно обеспечить приоритетную роль внутренних источников монетизации, сокращая остающуюся весьма высокой роль внешних источников [11].

В связи с этим изучение вопроса влияния кризиса, санкций на стоимость бизнеса и эффективность классических методов стоимостной оценки приобретает особую актуальность. Особую значимость изучение данного вопроса приобрело вследствие обострения текущего финансового кризиса в России в связи с введением экономических санкций в 2014 году.

2014 г. и особенно вторая его половина оказались весьма непростыми для российского финансового сектора. Антироссийские санкции западных стран и падение нефтяных цен при замедлении экономического роста и необходимости погашения внешних долгов вызвали рост турбулентности на финансовых рынках. Ситуация усугублялась действиями денежных властей, которые при недоступности внешних рынков вместо смягчения и создания более благоприятных условий на внутреннем рынке только ужесточали свои подходы. Как высказался ряд экспертов, в нестандартных условиях регулятор действовал стандартными методами, и предполагавшийся эффект достигнут не был [8].

В 2014 г. произошло снижение всех важнейших экономических показателей. Темпы 
роста ВВП по сравнению с 2013 г. снизились в 2,1 раза и составили $0,6 \%$, инвестиции в основной капитал достигли отрицательного значения, доля капиталовложений в экономику снизилась на $5,9 \%$ и составила $16,7 \%$, отток капитала составил 151,5 млрд долл., что в 5 раз превышает прогноз. Произошло изменение структуры совокупного спроса в связи с сокращением потребительского спроса: годовой темп роста расходов домашних хозяйств в 2014 г. снизился на 4 \% по сравнению с 2013 г. и составил $1,9 \%$. Снижение расходов домохозяйств вызвало уменьшение доли сбережений населения, которая снизилась на $3,3 \%$ по сравнению с 2013 г. и составила 7,8\%. На 2014 г. предельное значение инфляции было установлено на уровне $5 \%$, но уже в начале года произошло отклонение развития национальной экономики от установленных прогнозов, и в первом полугодии уровень инфляции находился на отметке $5,4 \%$. По итогам года инфляция составила $11,4 \%$, что является самым высоким показателем с 2008 г., когда потребительские цены выросли на 13,3 \%.

Сложившаяся экономическая и политическая ситуация повлияла на динамику валютного рынка, который в 2014 г. подвергся значительным колебаниям. На 1 ноября 2014 г. стоимость бивалютной корзины составила 46,80 руб., увеличение по сравнению с началом года произошло на 22,4 \%, снижение но- минального эффективного курса рубля к валютам стран - основных торговых партнеров России в октябре 2014 г. по отношению к декабрю 2013 г. - на 11,9 \% [22].

В 2014 г. произошло снижение капитализации отечественного фондового рынка: если в начале года капитализация составляла 766 млрд долл., то в конце года данный показатель снизился до 408 млрд долл. (снижение на 46,7 \%). Фондовый индекс с начала 2014 г. снизился более чем на $45 \%$ и стал худшим индексом в мире [10].

Затягивание кризиса чревато масштабированием экспортного риска, и для многих крупных предприятий фактически уже закрыто «экспортное окно» [21]. В основе кризиса лежат институциональные причины, которые вызвали низкие темпы социально-экономического развития страны за последнюю четверть века [18].

Финансовый кризис определяется как кризис, системно охватывающий финансовые рынки и институты финансового сектора, международные финансы, кредит и денежное обращение, государственные, муниципальные и корпоративные финансы [3]. Отметим, что у финансовых кризисов отмечается своя особенная периодичность - 6-8 лет, не совпадающая с очередностью известных циклов (цикл Китчина, цикл Кондратьева и др.) [5]. На рисунке показана периодичность финансовых кризисов.

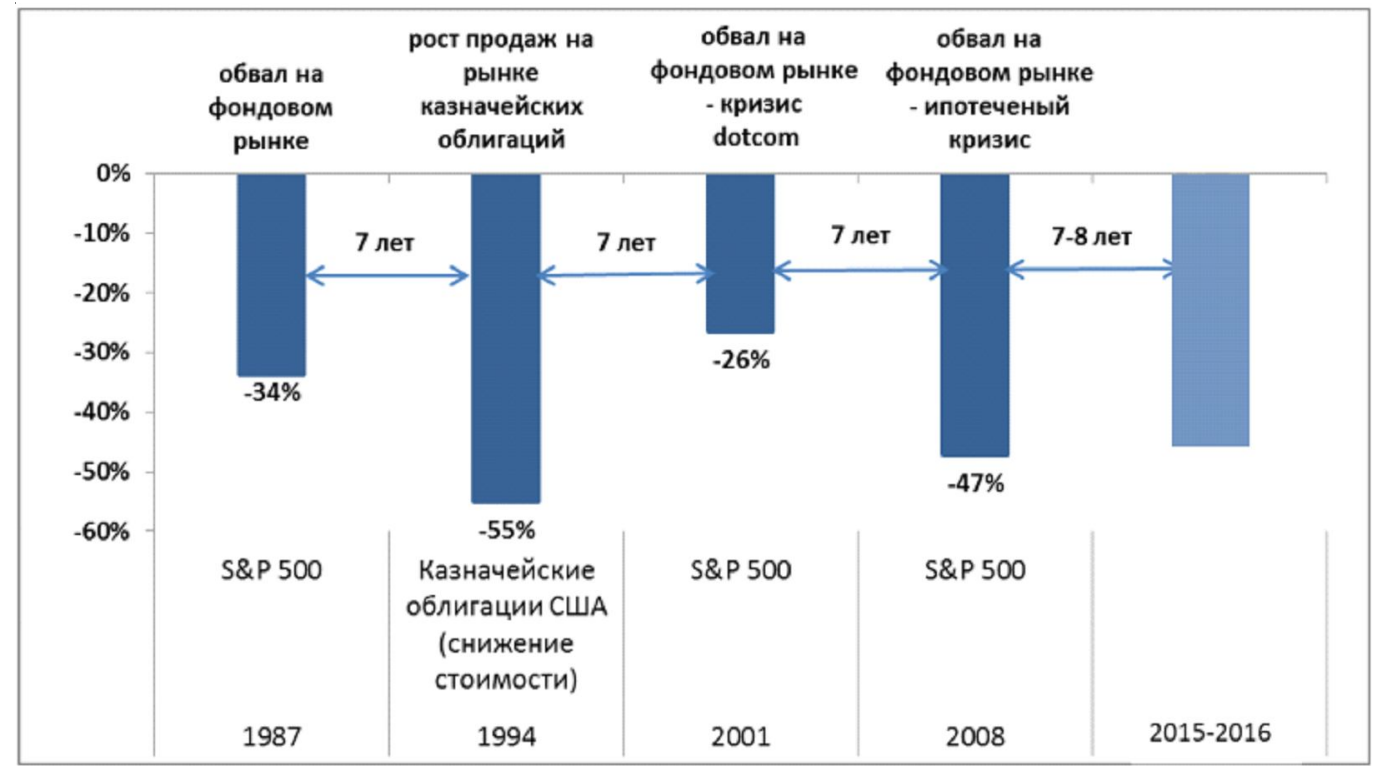

Рисунок. «Цикличность» провалов (динамика Индекса S\&P 500, \%)

Примечание. Составлено по: [7]. 
Текущий финансовый кризис не является чем-то неожиданным, и его наступление было вполне закономерным. Получается, что эти кризисы, будучи нечетко связаны с реальной экономикой, все равно имеют свою жесткую периодичность. Это дает возможность предположить либо свою собственную периодизацию циклов в финансовой сфере, либо их искусственный рукотворный характер, при котором они провоцируются для решения неких системных задач (передел сфер влияния, собственности и др.).

Текущий финансовый кризис в России повлиял на многие сферы деятельности [4], а также на стоимость компаний и их капитализацию. Эксперты отмечают, что снижение капитализации российских компаний во время кризиса чаще всего происходит значительными темпами и в больших масштабах. Рассмотрим изменение капитализации нескольких ведущих российских компаний различных отраслей в кризисные периоды (табл. 1).

Кризис 2009 г. оказал большее негативное воздействие на капитализацию российских компаний всех отраслей российской экономики, по сравнению с текущим финансовым кризисом. Однако говорить о каких-то результатах воздействия санкций 2014 г. рано, поскольку они еще не отменены, и негативные тенденции продолжают сохраняться в ряде отраслей. Стоит заметить, что некоторые предприятия (ГМК «Норильский никель» и ПАО «Полюс золото»), наоборот, повысили свою капитали- зацию за последние 2-3 года. Скорее всего, это связано с девальвацией рубля, поскольку доходы этих компаний номинированы в долларах, в то время как большинство расходов - в рублях. Следовательно, ослабление рубля для таких предприятий выгодно.

В период экономической нестабильности капитализация компаний, как мы уже выяснили, подвержена большим изменениям [6]. На наш взгляд, показатель стоимости бизнеса более стабилен, но в ситуации экономических кризисов его расчет затруднен. Классические методы стоимостной оценки перестают быть эффективными.

Оценка стоимости бизнеса включает в себя расчет стоимости всех активов компании: финансовых вложений, материальных активов, нематериальных активов (интеллектуальная собственность, бренд, гудвилл и пр.) [13]. Кроме того, оцениваются рентабельность, доходы компании, перспективы ее развития, внутриотраслевая конкуренция. Результаты такого комплексного анализа позволяют сравнить оцениваемую компанию с ее аналогами и дать объективную оценку бизнеса [15].

Сегодня в российской и зарубежной практике в соответствии со стандартами оценки активно используются три метода оценки стоимости бизнеса: доходный, сравнительный и затратный [17]. Каждый из данных подходов является индивидуальным и соответствует общепринятым в международной практике условиям.

Таблииа 1

Изменение капитализации ведущих российских компаний, млрд долл. США

\begin{tabular}{|l|l|c|c|c|c|c|c|c|c|}
\hline \multicolumn{1}{|c|}{$\begin{array}{l}\text { Название } \\
\text { компании }\end{array}$} & \multicolumn{1}{|c|}{ Отрасль } & 2007 г. & 2008 г. & 2009 г. & $\begin{array}{l}\text { Изменение в } \\
2009 \text { г. отно- } \\
\text { сительно } \\
2007 \text { г., } \%\end{array}$ & 2013 г. & 2014 г. & 2015 г. & $\begin{array}{c}\text { Изменение в } \\
2015 \text { г. отно- } \\
\text { сительно } \\
2013 \text { г., \% }\end{array}$ \\
\hline $\begin{array}{l}\text { ПАО «Газ- } \\
\text { пром» }\end{array}$ & $\begin{array}{l}\text { Нефтяная и } \\
\text { нефтегазовая } \\
\text { промышлен- } \\
\text { ность }\end{array}$ & 244,4 & 236,2 & 122,1 & $-50,0$ & 94,1 & 85,2 & 87,1 & $-7,4$ \\
\hline $\begin{array}{l}\text { ПАО «Сбер- } \\
\text { банк России» }\end{array}$ & Банки & 81,3 & 51,1 & 32,9 & $-59,5$ & 58,1 & 43,1 & 39,9 & $-31,3$ \\
\hline $\begin{array}{l}\text { ГКК «Нориль- } \\
\text { ский никель» }\end{array}$ & $\begin{array}{l}\text { Цветная ме- } \\
\text { таллургия }\end{array}$ & 42,1 & 37,6 & 20,4 & $-51,5$ & 20,9 & 31,2 & 39,2 & $+187,6$ \\
\hline $\begin{array}{l}\text { ПАО «Полюс } \\
\text { Золото» }\end{array}$ & $\begin{array}{l}\text { Промышлен- } \\
\text { ность драгме- } \\
\text { таллов и алма- } \\
\text { зов }\end{array}$ & 7,6 & 6,1 & 7,1 & $-6,6$ & 5,2 & 2,6 & 8,9 & $+171,2$ \\
\hline $\begin{array}{l}\text { ПАО «Ростеле- } \\
\text { ком» }\end{array}$ & $\begin{array}{l}\text { Телекоммуни- } \\
\text { кации и связь }\end{array}$ & 7,2 & 8,3 & 3,8 & $-47,2$ & 8,8 & 7,1 & 5,8 & $-34,1$ \\
\hline
\end{tabular}

Примечание. Составлено авторами. 
В рамках данных трех классических подходов используются также конкретные методы оценки: предприятия-аналога, накопления активов, избыточных прибылей, капитализации денежных потоков, дисконтирования.

В результате может быть рассчитана рыночная, инвестиционная, ликвидационная, фундаментальная и другие виды стоимости.

При этом процесс оценки стоимости компании напрямую зависит от побудивших ее причин и преследуемых ею целей. Определение цели предполагает выбор адекватного стандарта стоимости бизнеса. Проводя выбор необходимых методов для проведения процесса оценки бизнеса, необходимо представлять преимущества и недостатки, которые несет в себе каждый подход и метод.

В период относительной стабильности в экономике при расчетах стоимости бизнеса затратным методом оценивается, прежде всего, стоимость активов, которые имеются на балансе компании [26]. Используя сравнительный метод, бизнес оценивается по объектам-аналогам. Особенностью данного подхода является ориентация итоговой величины стоимости на два фактора: на рыночные цены купли-продажи акций, принадлежащих аналогичным компаниям, и на финансовые результаты, фактически достигнутые компаниями [27]. Применяя доходный метод, оценка бизнеса осуществляется с точки зрения ожи- дания будущих доходов, а также оценивается способность компании их генерировать. При этом учитываются такие факторы, как продолжительность получения ожидаемого дохода, степень риска и др. [7].

Каждый из рассматриваемых подходов предполагает использование нескольких методов расчета стоимости (табл. 2).

Показатели стоимости компании (бизнеса), выступая в роли инструмента измерения, должны носит нормативно-оценочный характер. В данном случае нормативность предполагает, что известно желаемое направление изменения значений показателей. Она является специфической чертой экономических измерений и обусловлена целенаправленностью поведения как объектов, так и субъектов измерения, целенаправленностью в использовании результатов измерений и результатов принятия решений. Необходимость нормативного подхода к изучению стоимости компании (бизнеса) обусловлена в том числе и тем, что стоимость играет роль критерия при принятии разнообразных решений, в частности, в плане стратегического управления предприятием.

Многие экономисты говорят о том, что в России начался и будет какое-то время продолжаться период кризиса [20]. Проблема оценки в кризис в том, что приходится производить оценку в условиях неработающих правил классической оценки. По словам оценщи-

Таблица 2

Методы расчета стоимости в различных подходах

\begin{tabular}{|c|c|c|}
\hline Затратный подход & Доходный подход & Сравнительный подход \\
\hline $\begin{array}{l}\text { 1. Метод стоимости чистых ак- } \\
\text { тивов }\end{array}$ & 1. Метод капитализации доходов & 1. Метод рынка капитала \\
\hline \multirow{3}{*}{$\begin{array}{l}\text { Стоимость компании определяется } \\
\text { разностью стоимости активов и } \\
\text { обязательств, которая выступает } \\
\text { своего рода ценой ее «гипотетиче- } \\
\text { ской продажи» на рынке }\end{array}$} & \multirow{3}{*}{$\begin{array}{l}\text { Стоимость бизнеса определяется } \\
\text { как отношение дохода за год к } \\
\text { ставке капитализации. Большин- } \\
\text { ством экспертов рекомендуется } \\
\text { при применении данного метода } \\
\text { использовать показатели дохода } \\
\text { до вычета НДФЛ }\end{array}$} & $\begin{array}{l}\text { Оценку бизнеса проводят исходя } \\
\text { из анализа рыночных цен акций } \\
\text { аналогичных компаний }\end{array}$ \\
\hline & & $\begin{array}{l}\text { 2. Метод отраслевых коэффици- } \\
\text { ентов }\end{array}$ \\
\hline & & $\begin{array}{l}\text { Стоимость бизнеса оценивается } \\
\text { исходя из статистики купли- } \\
\text { продажи аналогичных компаний }\end{array}$ \\
\hline $\begin{array}{l}\text { 2. Метод ликвидационной стои- } \\
\text { мости }\end{array}$ & $\begin{array}{l}\text { 2. Метод дисконтирования де- } \\
\text { нежных потоков }\end{array}$ & 3. Метод сделок \\
\hline $\begin{array}{l}\text { Стоимость компании определяется } \\
\text { разностью стоимости активов } \\
\text { предприятия и обязательств с уче- } \\
\text { том затрат на ликвидацию компа- } \\
\text { нии }\end{array}$ & $\begin{array}{l}\text { Для использования данного мето- } \\
\text { да необходимо прогнозирование } \\
\text { будущих доходов компании и дис- } \\
\text { контирование в соответствии с } \\
\text { требуемой ставкой дисконта }\end{array}$ & $\begin{array}{l}\text { Оценку бизнеса проводят с учетом } \\
\text { цен на приобретение контрольных } \\
\text { пакетов акций предприятий- } \\
\text { аналогов }\end{array}$ \\
\hline
\end{tabular}

Примечание. Составлено авторами. 
ков, даже в хорошие для российской экономики годы из обязательных трех подходов корректным был один или два [27].

Традиционно оценку бизнеса большинство аналитиков проводят с помощью доходного подхода методом дисконтирования денежных потоков, считая его наиболее точным. Однако в современный санкционный период российской экономики невозможно с высокой степенью достоверности прогнозировать денежные потоки, когда ситуация постоянно меняется. Кроме того, становится труднее рассчитать точную ставку дисконтирования и учесть в ней все финансовые риски [16].

При оценке рыночной стоимости доходным подходом можно рекомендовать вносить поправку в коэффициент дисконтирования, например, äî áàâëȳöü ï î ï đàâêó $\Delta i$ в составе коэффициента дисконтирования $(1 /(1+i+\Delta i)$. Данная поправка приближенно соответствует различию показателей инфляции в условиях кризиса $i_{G}$ и до кризиса $i$, следовательно, $\Delta i=i_{G}-i$.

Рассмотрим несколько способов определения поправки $\Delta i$, которые для наглядности приведены в таблице 3 .

Выбор одного из рекомендованных методов поправки для коэффициента дисконтирования, приведенных в таблице 2 , следует проводить на основе анализа макроэкономических показателей.
Таким образом, введение поправок для оценки сравнительным подходом нецелесообразно, так как аналоги определяются на сегменте рынка в условиях кризиса, в чем и состоит учет фактора кризиса при оценке стоимости. Для эффективного применения сравнительного подхода в оценке стоимости бизнеса необходимо функционирование развитого рынка активов, наличие информации о суммах сделок купли-продажи, сделок слияний и поглощений, котировок акций аналогов. В связи с неразвитостью рынка акций, отсутствием открытых, прозрачных данных о расчетной или фактической стоимости предприятий и их акций в России этот подход редко используется.

Затратный способ использовать для оценки стоимости бизнеса в настоящее время не совсем целесообразно, так как разница между активами и обязательствами компании может быть очень низкой и поэтому стоимость бизнеса, рассчитанная по данному подходу, не отражает в полной мере действительность.

При оценке затратным подходом в условиях кризиса фактор внешнего износа (снижения стоимости актива по причине ухудшения рынка) можно по рассмотренным выше рекомендациям учесть согласованно с оценкой поправки $\Delta i$ для коэффициента дисконтирования. Внешний износ для оценки затрат-

\section{Практические приемы определения поправки $\Delta i$ для коэффициента дисконтирования}

\begin{tabular}{|c|c|}
\hline Способ определения поправки $\Delta i$ & Пример \\
\hline $\begin{array}{l}\text { 1. Исходя из данных о различии зна- } \\
\text { чений показателя инфляции по срав- } \\
\text { нению с докризисным значением }\end{array}$ & $\begin{array}{l}\text { Например, по данным об инфляции в } 2013 \text { г. }(6,5 \%) \text { и в } 2014 \text { г. } \\
(11,4 \%) \text { поправка составляет } \Delta i \approx 11,4-6,5==4,9 \%=0,049 ; \text { соот- } \\
\text { ветственно, ставка дисконтирования } i \text { определяется для условий } \\
2015 \text { г., а поправка равна 4,9\%, если при этом прогнозировать та- } \\
\text { кие же темпы роста инфляции в } 2015 \text { г. }\end{array}$ \\
\hline $\begin{array}{l}\text { 2. На основе изменения валютного } \\
\text { курса }\end{array}$ & $\begin{array}{l}\text { С учетом различия валютного курса } B K \text { в условиях кризиса и до } \\
\text { кризиса (например, } 32 \text { руб./долл. США), поправка для коэффициен- } \\
\text { та дисконтирования составляет } \Delta i \approx B K /(32)-1 \text {. } \\
\text { Примечание. Ставка дисконтирования определяется в условиях } \\
2015 \text { г. (или иного текущего кризисного года), и в течение данного } \\
\text { года продолжится рост обменного курса, сопоставимый с ростом } \\
\text { курса в } 2014 \text { г. }\end{array}$ \\
\hline $\begin{array}{l}\text { 3. С учетом зависимости валютного } \\
\text { курса от стоимости на бирже фьючер- } \\
\text { сов барреля нефти РО (Price Oil, } \\
\text { руб./долл. США) }\end{array}$ & $\begin{array}{l}B K=3600 / \text { РО (руб./долл. США), предложенную выше рекоменда- } \\
\text { цию (см. п. 2) можно представить в форме: } \Delta i \approx 110 / \text { PO - } 1\end{array}$ \\
\hline
\end{tabular}

Примечание. Составлено авторами по: [6]. 
ным подходом равен $\Delta D=\Delta i /(I+\Delta i)$, соответственно ставка дисконтирования $i$ определяется для условий 2015 г. (или иного текущего кризисного года), а поправка $\Delta i-$ на основе рекомендаций, рассмотренных выше.

Повышению точности отчетов об оценке способствовала бы возможность получения оценщиками более качественной исходной информации. Проблема своевременности, достоверности и адекватности информации о ценах реальных сделок становится в последнее время все более острой. Неразрешенность проблемы недоступности ценовой информации для оценщиков - коренное отличие российской оценки от зарубежной.

В последнее время падает роль традиционных методов оценки, в связи с чем возрастает значимость современных подходов (опционного, расчета рыночной стоимости компании методами EVA, SVA, MVA и др.). В то же время представляется необходимым совершенствование классических подходов к оценке бизнеса. Например, повысить эффективность использования метода дисконтирования денежных потоков можно с помощью более полного учета рисков в ставке дисконтирования за счет включения в нее не только финансовых, но и нефинансовых рисков.

\section{СПИСОК ЛИТЕРАТУРЫ}

1. Архипов, В. М. Стратегическое управление / В. М. Архипов. - СПб. : Изд-во СПбГУЭФ, 2000. $245 \mathrm{c}$.

2. Буянова, М. Э. Регионы юга России: угрозы и риски в новых условиях социально-экономического развития / М. Э. Буянова // Экономическое развитие России: драйвер роста или генератор вызовов : материалы Междунар. науч.-практ. конф. Сочи : Изд-во КубГУ, 2016. - С. 103-106.

3. Васина, Е. В. Мировые финансовые кризисы и их виды / Е. В. Васина // Вестник МГИМОУниверситета. - 2015. - № 4 (43). - С. 271-277.

4. Винничек, Л. Б. Методические аспекты организации бюджетирования / Л. Б. Винничек, Е. В. Фудина // Вестник Ульяновской государственной сельскохозяйственной академии. - 2011. № 2. - C. 138-142.

5. Винничек, Л. Б. Повышение эффективности и устойчивости сельскохозяйственного производства / Л. Б. Винничек, Е. В. Фудина // Международный сельскохозяйственный журнал. - 2009. № 5. - C. 17-19.
6. Винничек, Л. Б. Производственный потенциал: теория вопроса / Л. Б. Винничек, А. А. Колобов // Региональная экономика: теория и практика. -2011. - № 7. - С. 42-46.

7. Войлошников, М. Оценка стоимости в кризисный период / М. Войлошников // Оценочная деятельность. - 2015. - № 1. - С. 36-39.

8. Глазьев, С. Санкции США и политика Банка России: двойной удар по национальной экономике / С. Глазьев // Вопросы экономики. - 2014. № 9. - С. 13-29.

9. Грибцов, С. В. Стоимость бизнеса как основной целевой показатель стратегического развития предприятия / С. В. Грибцов // Вестник Саратовского государственного социально-экономического университета. - 2009. - № 5. - С. 69-72.

10. Деникаева, Р. Н. Механизм антикризисного управления в российской экономике и в зарубежных странах / Р. Н. Деникаева // Экономический анализ: теория и практика. - 2008. - № 4. - С. 39-45.

11. Ершов, М. В. Об обеспечении валютной стабильности и о новых финансовых механизмах в условиях санкционного режима / М. В. Ершов // Российский экономический журнал. - 2014. - № 5. C. 22-30.

12. Ершов, М. В. Растущая угроза мирового финансового кризиса / М. В. Ершов // Аналитический банковский журнал. - 2015. - № 8. - С. 10-12.

13. Журавлев, И. Е. Влияние факторов макроэкономики на стоимость бизнеса / И. Е. Журавлев, Н. В. Лысова // Череповецкие научные чтения-2016 : материалы Всерос. науч.-практ. конф. - Череповец : Изд-во Череповец. гос. ун-та, 2016. - С. 62-64.

14. Зарук, Н. Ф. Управление финансовой устойчивостью предприятий / Н. Ф. Зарук, Л. Б. Винничек // АПК: Экономика, управление. - 2002. № 12. - С. $56-61$.

15. Зингер, О. А. Факторы, влияющие на устойчивое развитие промышленных предприятий / О. А. Зингер, А. В. Ильясова // Современные проблемы науки и образования. - 2015. - № 1-1. - С. 591.

16. Ильина, Е. В. Влияние санкций на экономику России / Е. В. Ильина // Вестник экономики, права и социологии. - 2015. - № 4. - С. 34-38.

17. Киндаев, А. Ю. Моделирование процессов страхования в сельском хозяйстве / А. Ю. Киндаев // Модели, системы, сети в экономике, технике, природе и обществе. - 2014. - № 2 (10). - С. 91-96.

18. Котова, Л. А. Долгосрочные перспективы позиционирования юга России и региона «Донбасс» в интеграционном процессе формирования коридора развития / Л. А. Котова, И. В. Митрофанова // Региональная экономика. Юг России. 2015. - № 4 (10). - С. 23-37.

19. Малухин, Д. А. Стоимость бизнеса как ключевой критерий оценки эффективности управ- 
ления развитием предприятия / Д. А. Малухин, Д. П. Бирман // Вестник Нижегородского университета им. Н.И. Лобачевского. Серия: Экономика и финансы. - 2004. - № 2. - С. 565-569.

20. Мамедов, А. А. Международное право в управлении экономикой в условиях глобализации / А. А. Мамедов // Международное публичное и частное право. - 2014. - № 6. - С. 14-16.

21. Митрофанова, И. В. Риски, ограничения и перспективы экономического сотрудничества южных регионов России и Украины / И. В. Митрофанова // Экономика и управление: проблемы, решения. - 2016. - № 7. - С. 10-18.

22. Молитвик, В. Н. Россия в условиях кризиca: анализ основных показателей / В. Н. Молитвик, Р. Н. Деникаева // Экономика и управление: проблемы, решения. - 2015. - № 11. - С. 122-124.

23. Павлов, А. Ю. Методика определения перспективного направления аграрного развития муниципальных образований (на примере Пензенской области) / А. Ю. Павлов, М. С. Афанасьева // Вестник НГИЭИ. - 2016. - № 12 (67). - С. 101-106.

24. Соколов, А. Ю. Административная ответственность за нарушения антимонопольного законодательства : дис. ... канд. юрид. наук / Соколов Александр Юрьевич. - Саратов, 2004. - 213 с.

25. Яновский, В. В. Методические аспекты влияния инвестиций на стоимость бизнеса / В. В. Яновский, С. В. Проскурников // Вестник Белгородского университета кооперации, экономики и права. 2009. - № 4-2. - C. 165-169.

26. Evolutional-genetic approach to formation of sustainable development indicators of the agricultural territories / V. V. Rassadin, A. J. Pavlov, V. N. Batova, A. V. Kolesnikov // Journal of Environmental Management and Tourism. - 2014. - Vol. 5, № 2 (10). P. 230-236. - DOI: http://dx.doi.org/10.14505/jemt. v5.2(10). 05 .

27. Problems of state regulation of innovation policy in the Russian Federation and foreign countries / A. J. Pavlov, V. N. Batova, N. N. Kovalyova, A. V. Kolesnikov, A. Y. Sokolov, Y. V. Soboleva // Journal ofAdvanced Research in Law and Economics. - 2015. Vol. 6, № 4. - P. 802-821. - DOI: 10.14505/jarle.v6. 4(14). 10 .

\section{REFERENCES}

1. Arkhipov V.M. Strategicheskoe upravlenie [Strategic Management]. Saint Petersburg, Izd-vo SPbGUEF, 2000. 245 p.

2. Buyanova M.E. Regiony yuga Rossii: ugrozy i riski $\mathrm{v}$ novykh usloviyakh sotsialnoekonomicheskogo razvitiya [The Regions of the South of Russia: Threats and Risks in the New Conditions of
Socio-Economic Development]. Ekonomicheskoe razvitie Rossii: drayver rosta ili generator vyzovov: materialy Mezhdunar. nauch.-prakt. konf. [Russia's Economic Development: Driver of Growth or a Generator of Challenges. Proceedings of International Scientific-Practical Conference]. Sochi, Izd-vo KubGU, 2016, pp. 103-106.

3. Vasina E.V. Mirovye finansovye krizisy i ikh vidy [Global Financial Crises and Their Types]. Vestnik MGIMO-Universiteta, 2015, no. 4 (43), pp. 271-277.

4. Vinnichek L.B., Fudina E.V. Metodicheskie aspekty organizatsii byudzhetirovaniya [Methodological Aspects of Budgeting]. Vestnik Ulyanovskoy gosudarstvennoy selskokhozyaystvennoy akademii, 2011, no. 2, pp. 138-142.

5. Vinnichek L.B., Fudina E.V. Povyshenie effektivnosti i ustoychivosti selskokhozyaystvennogo proizvodstva [Improving the Efficiency and Sustainability of Agricultural Production]. Mezhdunarodnyy selskokhozyaystvennyy zhurnal, 2009, no. 5, pp. 17-19.

6. Vinnichek L.B., Kolobov A.A. Proizvodstvennyy potentsial: teoriya voprosa [Production Potential: Theory of the Issue]. Regionalnaya ekonomika: teoriya i praktika, 2011, no. 7, pp. 42-46.

7. Voyloshnikov M. Otsenka stoimosti v krizisnyy period [Valuation during the Crisis Period]. Otsenochnaya deyatelnost, 2015, no. 1, pp. 36-39.

8. Glazyev S. Sanktsii SShA i politika Banka Rossii: dvoynoy udar po natsionalnoy ekonomike [The USA Sanctions and the Policy of Bank of Russia: Double Blow to National Economy]. Voprosy ekonomiki, 2014, no. 9, pp. 13-29.

9. Gribtsov S.V. Stoimost biznesa kak osnovnoy tselevoy pokazatel strategicheskogo razvitiya predpriyatiya [The Value of Business as the Main Target for Strategic Development of an Enterprise]. Vestnik Saratovskogo gosudarstvennogo sotsial'noekonomicheskogo universiteta, 2009, no. 5, pp. 69-72.

10. Denikaeva R.N. Mekhanizm antikrizisnogo upravleniya $\mathrm{v}$ rossiyskoy ekonomike i v zarubezhnykh stranakh [The Mechanism of Crisis Management in Russian Economy and in Foreign Countries]. Ekonomicheskiy analiz: teoriya i praktika, 2005, no. 4, pp. 39-45.

11. Ershov M.V. Ob obespechenii valyutnoy stabilnosti i o novykh finansovykh mekhanizmakh v usloviyakh sanktsionnogo rezhima [On Ensuring Monetary Stability and on Innovative Financial Mechanisms in the Context of Sanction Regime]. Rossiyskiy ekonomicheskiy zhurnal, 2014, no. 5, pp. 22-30.

12. Ershov M.V. Rastushchaya ugroza mirovogo finansovogo krizisa [The Growing Threat of the Global Financial Crisis]. Analiticheskiy bankovskiy zhurnal, 2015, no. 8, pp. 10-12. 
13. Zhuravlev I.E., Lysova N.V. Vliyanie faktorov makroekonomiki na stoimost biznesa [The Impact of Macroeconomics Factors on the Value of Business]. Cherepovetskie nauchnye chteniya-2016: materialy Vseros. nauch.-prakt. konf. [Cherepovets Scientific Readings - 2016: Materials of All-Russian ScientificPractical Conference]. Cherepovets, Izd-vo Cherepovets. gos. un-ta, 2016, pp. 62-64.

14. Zaruk N.F., Vinnichek L.B. Upravlenie finansovoy ustoychivostyu predpriyatiy [Management of Financial Stability of Enterprises]. APK: Ekonomika, upravlenie [Agro-Industrial Complex: Economics, management], 2002, no. 12, pp. 56-61.

15. Zinger O.A., Ilyasova A.V. Faktory, vliyayushchie na ustoychivoe razvitie promyshlennykh predpriyatiy [The Factors Influencing the Sustainable Development of Industrial Enterprises]. Sovremennye problemy nauki i obrazovaniya, 2015, no. 1-1, p. 591.

16. Ilyina E.V. Vliyanie sanktsiy na ekonomiku Rossii [The Impact of Sanctions on the Russian Economy]. Vestnik ekonomiki, prava i sotsiologii, 2015, no. 4, pp. 34-38.

17. Kindaev A.Yu. Modelirovanie protsessov strakhovaniya $\mathrm{v}$ selskom khozyaystve [Modeling the Processes of Insurance in Agriculture]. Modeli, sistemy, seti $v$ ekonomike, tekhnike, prirode $i$ obshchestve, 2014, no. 2 (10), pp. 91-96.

18. Kotova L.A., Mitrofanova I.V. Dolgosrochnye perspektivy pozitsionirovaniya yuga Rossii i regiona «Donbass» v integratsionnom protsesse formirovaniya koridora razvitiya [Long-Term Prospects of Positioning Southern Russia and the Region "Donbass" in the Integration Process of Forming the Development Corridor]. Regionalnaya ekonomika. Yug Rossii, 2015, no. 4 (10), pp. 23-37.

19. Malukhin D.A., Birman D.P. Stoimost biznesa kak klyuchevoy kriteriy otsenki effektivnosti upravleniya razvitiem predpriyatiya [The Value of the Business as a Key Criterion for Assessing the Effectiveness of Management of Enterprise Development]. Vestnik Nizhegorodskogo universiteta im. N.I. Lobachevskogo. Seriya: Ekonomika i finansy, 2004, no. 2, pp. 565-569.

20. Mamedov A.A. Mezhdunarodnoe pravo $v$ upravlenii ekonomikoy $\mathrm{v}$ usloviyakh globalizatsii
[International Law in Managing the Economy under the Conditions of Globalization]. Mezhdunarodnoe publichnoe i chastnoe pravo, 2014, no. 6, pp. 14-16.

21. Mitrofanova I.V. Riski, ogranicheniya i perspektivy ekonomicheskogo sotrudnichestva yuzhnykh regionov Rossii i Ukrainy [Risks, Limitations and Prospects of Economic Cooperation in the Southern Regions of Russia and Ukraine]. Ekonomika $i$ upravlenie: problemy, resheniya, 2016, no. 7, pp. 10-18.

22. Molitvik V.N., Denikaeva R.N. Rossiya v usloviyakh krizisa: analiz osnovnykh pokazateley [Russia in Crisis: Analysis of the Main Indicators]. Ekonomika i upravlenie: problemy, resheniya, 2015, no. 11, pp. 122-124.

23. Pavlov A.Yu., Afanasyeva M.S. Metodika opredeleniya perspektivnogo napravleniya agrarnogo razvitiya munitsipalnykh obrazovaniy (na primere Penzenskoy oblasti) [Technique of Definition of the Perspective Direction of Agrarian Development of Municipalities (on the Example of the Penza Region)]. Vestnik NGIEI, 2016, no. 12 (67), pp. 101-106.

24. Sokolov A.Yu. Administrativnaya otvetstvennost za narusheniya antimonopolnogo zakonodatelstva: dis. ... kand. yurid. naukk [Administrative Liability for Violations of Antimonopoly Legislation. Cand. jurid. sci. diss.]. Saratov, 2004. $213 \mathrm{p}$.

25. Yanovskiy V.V., Proskurnikov S.V. Metodicheskie aspekty vliyaniya investitsiy na stoimost biznesa [Methodological Aspects of the Impact of Investments on Business Value]. Vestnik Belgorodskogo universiteta kooperatsii, ekonomiki i prava, 2009, no. 4-2, pp. 165-169.

26. Rassadin V.V., Pavlov A.J., Batova V.N., Kolesnikov A.V. Evolutional-genetic approach to formation of sustainable development indicators of the agricultural territories. Journal of Environmental Management and Tourism, 2014, vol. 5, no. 2 (10), pp. 230-236. DOI: http://dx.doi.org/10.14505/ jemt.v5.2(10).05.

27. Pavlov A.J., Batova V.N., Kovaleva N.N., Kolesnikov A.V., Sokolov A.Y., Soboleva Y.V. Problems of state regulation of innovation policy in the Russian Federation and foreign countries. Journal of Advanced Research in Law and Economics, 2015, vol. 6, no. 4, pp. 802-821. DOI: 10.14505/jarle.v6.4(14).10. 


\section{Information About the Authors}

Yuliya A. Kaftulina, Candidate of Sciences (Economics), Associate Professor, Department of Economic Theory and International Relations, Penza State University, Krasnaya St., 40, 440026 Penza, RussianFederation, ulya_01@list.ru.

Vera N. Batova, Associate Professor, Department of Economics and Management, Penza State Technological University, Baydukova Passway / Gagarina St., 1A/11, 440039 Penza, Russian Federation, batova.v.n@yandex.ru.

Inna A. Mitrofanova, Candidate of Sciences (Economics), Associate Professor, Department of Economics and Management, Volgograd State Technical University, Prosp. Lenina, 28, 400005 Volgograd, Russian Federation, mia05011986@yandex.ru.

Yuliya I. Rusakova, Master Student, Penza State University, Krasnaya St., 40, 440026 Penza, RussianFederation, lafik-15@mail.ru.

\section{Информация об авторах}

Юлия Анатольевна Кафтулина, кандидат экономических наук, доцент кафедры экономической теории и международных отношений, Пензенский государственный университет, ул. Красная, 40, 440026 г. Пенза, Российская Федерация, ulya_01@list.ru.

Вера Николаевна Батова, доцент кафедры экономики и управления, Пензенский государственный технологический университет, проезд Байдукова/ул. Гагарина, 1a/11, 440039 г. Пенза, Российская Федерация, batova.v.n@yandex.ru.

Инна Алексеевна Митрофанова, кандидат экономических наук, доцент кафедры экономики и управления, Волгоградский государственный технический университет, просп. Ленина, 28, 400005 г. Волгоград, Российская Федерация, mia05011986@yandex.ru.

Юлия Игоревна Русакова, магистрант, Пензенский государственный университет, ул. Красная, 40, 440026 г. Пенза, Российская Федерация, lafik-15@mail.ru. 